\title{
Growth of ZnO Nanowires Catalyzed by Size- Dependent Melting of Au Nanoparticles
}

\section{Citation}

Petersen, Eric W., Edward M. Likovich, Kasey J. Russell, and Venkatesh Narayanamurti. 2009. Growth of ZnO nanowires catalyzed by size-dependent melting of Au nanoparticles. Nanotechnology 20(40): 405603.

\section{Published Version}

doi:10.1088/0957-4484/20/40/405603

\section{Permanent link}

http://nrs.harvard.edu/urn-3:HUL.InstRepos:3606240

\section{Terms of Use}

This article was downloaded from Harvard University's DASH repository, and is made available under the terms and conditions applicable to Open Access Policy Articles, as set forth at http:// nrs.harvard.edu/urn-3:HUL.InstRepos:dash.current.terms-of-use\#OAP

\section{Share Your Story}

The Harvard community has made this article openly available.

Please share how this access benefits you. Submit a story.

\section{Accessibility}




\title{
Growth of $\mathrm{ZnO}$ nanowires catalyzed by size-dependent melting of Au nanoparticles
}

\author{
Eric W. Petersen, Edward M. Likovich," Kasey J. Russell, and Venkatesh Narayanamurti \\ School of Engineering and Applied Sciences, \\ Harvard University, Cambridge, Massachusetts 02138
}

(Dated: December 22, 2009)

\begin{abstract}
We present a general approach to growing $\mathrm{ZnO}$ nanowires on arbitrary, high melting-point (above $970^{\circ} \mathrm{C}$ ) substrates using the Vapor-Liquid-Solid (VLS) growth mechanism. Our approach utilizes the melting point reduction of sufficiently small (5 $\mathrm{nm}$ diameter) Au particles to provide a liquid catalyst without substrate interaction. Using this size-dependent melting effect, we demonstrate catalytic VLS growth of ZnO nanowires on both $\mathrm{Ti}$ and Mo foil substrates with aspect ratios in excess of 1000:1. Transmission electron microscopy shows the nanowires to be single-crystalline, and photoluminescence spectra show high-quality optical properties. We believe this growth technique to be widely applicable to a variety of substrates and material systems.
\end{abstract}

PACS numbers:

*Electronic address: likovich@post.harvard.edu 
The Vapor-Liquid-Solid (VLS) growth mechanism, first demonstrated by Wagner and Ellis [1], has become a widely-used method for synthesizing semiconductor nanowires [2, 3]. In VLS growth, a liquid catalyst serves as a site for preferential adsorption of the gaseous source material, and the nanowire precipitates upon supersaturation of the catalyst droplet. The VLS mechanism is desirable because growth from a liquid catalyst proceeds 10-100 times more rapidly than growth from a solid catalyst [4]. VLS growth of ZnO nanowires has been extensively studied due to the favorable optoelectronic properties of $\mathrm{ZnO}$, which include a wide bandgap (3.37 eV), strong exciton binding energy (60 meV), and potential use as a transparent conductor [5-7]. Typically, VLS growth of ZnO nanowires relies on the eutectic formed at the interface between a Au catalyst and a Si substrate. This eutectic melts at a lower temperature than either $\mathrm{Au}$ or Si independently, thereby enabling VLS growth to occur at temperatures below that needed for comparable rates of direct vaporsolid growth. However, because Si from the substrate is necessary for the catalyst to liquefy, this method is not simply translatable to other growth substrates. A generic approach to nanowire growth that is substrate-independent could enable growth on flexible, conductive, and low-cost substrates.

Efforts have been made to generalize nanowire growth to metallic substrates, including the growth of $\mathrm{CdS}$ nanowires from $\mathrm{Cd}$ foil via a solution synthesis method [8, 9] and $\mathrm{ZnO}$ growth from catalyst-free oxidation of brass and $\mathrm{Zn}$ foil $[10,11]$. However, these methods are ultimately limiting in that they rely on the substrate to provide source material for nanowire growth. Other methods include seeding the surface with $\mathrm{ZnO}$ catalysts [12], which appears to be limited to solution-synthesis; using Al foil as a mask for supersaturation, which lacks the ability to control growth position through catalyst positioning [13]; and sputtering $\mathrm{Au} / \mathrm{Pd}$ catalyst onto the substrate prior to growth, which requires a reaction between the catalyst and substrate for growth [14].

Here we demonstrate a simple and generic approach to VLS growth of ZnO nanowires that utilizes size-dependent melting [15-17] of nanometer-scale Au particles (typically $\sim 5 \mathrm{~nm}$ diameter) to provide a liquid catalyst without any substrate interaction. We demonstrate this method on both $\mathrm{Ti}$ and Mo foil substrates and expect it to be applicable to a variety of nanowire materials, catalysts, and high melting-point substrates.

The growth apparatus used for this experiment consisted of a single-zone tube furnace (from Lindberg/Blue) through which we passed a metered flow of $\mathrm{Ar}$ and $\mathrm{O}_{2}$ in a 1000:1 ratio. 
A quartz sample holder, containing both the substrate and a mixture of ZnO powder and graphite (1:1 ratio by volume), was used to move the substrate in and out of the hot zone of the furnace, thereby initiating and terminating nanowire growth. Ti foil (from Alfa Aesar) and Mo foil (from Aldrich) were used as substrates. These were first cleaned in acetone and ethanol and then rinsed in deionized water. Au catalyst nanoparticles suspended in an aqueous solution (from BBInternational) were deposited from a pipet onto the metal foil substrates and allowed to air dry, which left a characteristic ring-shaped deposit of clustered nanoparticles along the initial contact line of the droplet. Positional and density control of Au nanoparticle monolayers has been demonstrated in the literature; [18] here, we focus on a demonstration of nanowire growth using size-dependent melting.

We used both $5 \mathrm{~nm}$ and $30 \mathrm{~nm}$ diameter Au particles. According to the literature, the melting point of a $5 \mathrm{~nm}$ Au particle is depressed to approximately $750-850^{\circ} \mathrm{C}$, while a $30 \mathrm{~nm}$ particle melts at the bulk temperature of $1064^{\circ} \mathrm{C}$ [16]. Thus $5 \mathrm{~nm}$ particles should liquefy while $30 \mathrm{~nm}$ particles remain solid at the growth temperature of $975^{\circ} \mathrm{C}$. We confirmed this by annealing the as-deposited particles (Figures $1 \mathrm{a}$ and $1 \mathrm{~b}$ ) at $975^{\circ} \mathrm{C}$ for 3 hours. The annealing took place under conditions identical to those used for nanowire growth, except that no $\mathrm{ZnO}$ or graphite source powder was present. Figure 1c shows the sample with $5 \mathrm{~nm}$ particles that displays agglomeration characteristic of melting, whereas the sample with 30 $\mathrm{nm}$ particles shows no such agglomeration (Figure 1d), indicating the the $30 \mathrm{~nm}$ particles did not melt. Extended annealing (24 hours) at lower temperature $\left(400^{\circ} \mathrm{C}\right)$ showed no agglomeration for either particle size. Since no eutectic exists between $\mathrm{Au} / \mathrm{Ti}$ or $\mathrm{Au} / \mathrm{Mo}$ at the growth temperature, we attribute the melting of the $5 \mathrm{~nm}$ particles to nanometer-scale size effects that are independent of the substrate.

Because the VLS mechanism requires a liquid catalyst, we expect $\mathrm{ZnO}$ nanowire growth to occur only on the substrate containing $5 \mathrm{~nm} \mathrm{Au}$ particles and not on that containing 30 $\mathrm{nm} \mathrm{Au}$ particles. After a growth of 45 minutes at $975^{\circ} \mathrm{C}, \mathrm{ZnO}$ nanowires were present only on the samples containing $5 \mathrm{~nm}$ Au particles and grew only on the part of the metal foil covered by Au catalyst. A typical growth using $5 \mathrm{~nm}$ particles on Mo foil is shown in Figures $2 \mathrm{a}$ and $2 \mathrm{~b}$, which shows extensive growth of $\mathrm{ZnO}$ nanowires. The wires ranged in length from 10-30 $\mu \mathrm{m}$ and in diameter from 100-300 $\mathrm{nm}$ and also exhibited a small catalyst particle at their tip, characteristic of VLS growth. This is contrasted by the lack of nanowires in the post-growth image (Figure 2c) of the foil patterned with $30 \mathrm{~nm}$ Au particles, which instead 

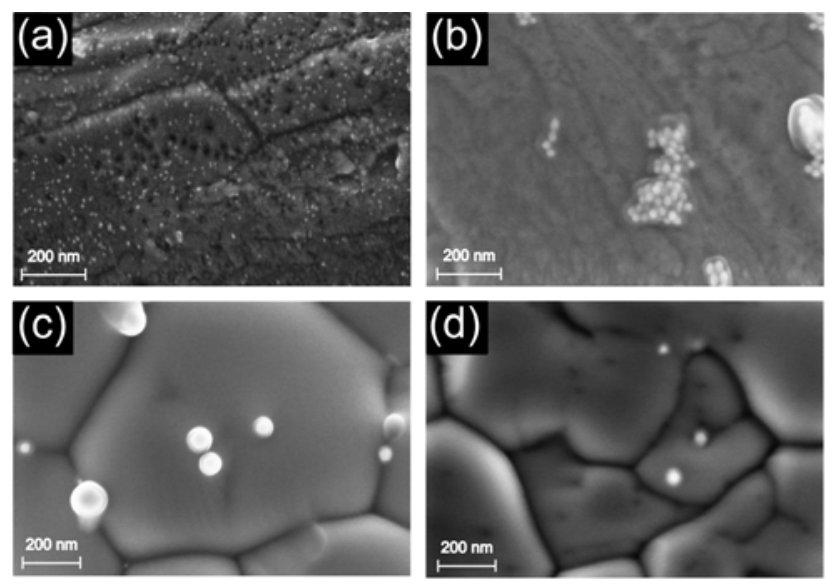

FIG. 1: Scanning Electron Microscopy (SEM) images using a Zeiss Ultra 55 at $5 \mathrm{kV}$ with a working distance of $8 \mathrm{~mm}$. (a) SEM image of the as-deposited $5 \mathrm{~nm} \mathrm{Au} \mathrm{nanoparticle} \mathrm{catalysts} \mathrm{on} \mathrm{Mo} \mathrm{foil.}$ (b) SEM image of the as-deposited $30 \mathrm{~nm} \mathrm{Au} \mathrm{nanoparticle} \mathrm{catalysts} \mathrm{on} \mathrm{Mo} \mathrm{foil.} \mathrm{(c)} \mathrm{SEM} \mathrm{image}$ of the $5 \mathrm{~nm} \mathrm{Au}$ nanoparticles post-annealing. We believe that the presence of such large (50-150 $\mathrm{nm})$ particles is the result of agglomeration as the $5 \mathrm{~nm}$ particles melt, which is contrasted with the (d) SEM image of the $30 \mathrm{~nm}$ Au nanoparticles post-annealing, in which the particles retain their initial diameter of $30 \mathrm{~nm}$ and do not exhibit any agglomeration.

catalyzed only bulk ZnO growth (EDS analysis of the surface revealed significant traces of Mo, Zn, and O).

In order to demonstrate the generality of our method, we repeated the growth procedure described above on Ti foil substrates, which like Mo do not melt or form a eutectic with gold at the growth temperature. Robust VLS growth was also achieved from the $5 \mathrm{~nm} \mathrm{Au}$ particles on the Ti foil, whereas no nanowire growth was observed on the sample containing $30 \mathrm{~nm}$ particles. The growth does not seem to be entirely substrate-independent however, as wires grown on the Ti foil were thinner (40-70 nm diameter, compared to 100-300 nm for those grown on Mo foil) and were often accompanied by sail-like structures. This may be a result of the native surface oxide that forms on $\mathrm{Ti}$, although further investigation is needed.

Room-temperature photoluminescence measurements were conducted to confirm that the nanowires were, indeed, ZnO. Figure 3 shows a characteristic PL spectrum from nanowires on $\mathrm{Ti}$ and Mo, showing band-edge luminescence of the wires at approximately $3.28 \mathrm{eV}$ close to the $3.37 \mathrm{eV}$ bandgap of $\mathrm{ZnO}$. This red shift in the band-edge emission is consistent with other reports in the literature and may be the result of band lowering effects such 
as Stokes shift, or defect and impurity states [19]. We attribute the broad sub-bandgap peak near $2.5 \mathrm{eV}$ from the wires grown on Ti foil to surface defects, such as singly ionized oxygen vacancies [20]. This feature is much less strong in wires grown on Mo foil, which is consistent with reports that correlate nanowire diameter with band-edge and sub-band peak intensity [21]. Transmission Electron Microscopy (TEM) diffraction (inset of Figure 3) shows that our nanowires have high-quality single-crystal wurtzite structure, as commonly reported in literature [22].

In conclusion, we have demonstrated a substrate-independent approach to growing $\mathrm{ZnO}$ nanowires that utilizes the size-dependent melting effect of small Au particles. We believe that this method can be extended to other materials systems grown by the VLS method and, because of the universal nature of size-dependent melting [15, 17], can also be used with a variety of catalyst materials. This approach could be one method of generalizing nanowire growth to a variety of substrates and materials.

\section{Acknowledgments}

This work was supported by NSF/NNIN through the use of their facilities at Harvard University's Center for Nanoscale Systems (CNS). The authors appreciate the assistance of W. Yi and M. Zimmler for photoluminescence measurements and D. Lange for EDS characterization. E.M.L. acknowledges a U.S. Department of Homeland Security Graduate Research Fellowship.

[1] R. S. Wagner and W. C. Ellis, Appl. Phys. Lett. 4, 89 (1964).

[2] Y. Cui, L. J. Lauhon, M. S. Gudiksen, J. Wang, and C. M. Lieber, Appl. Phys. Lett. 78, 2214 (2001).

[3] A. M. Morales and C. M. Lieber, Science 279, 208 (1998).

[4] S. Kodambaka, J. Tersoff, M. C. Reuter, and F. M. Ross, Science 316, 729 (2007).

[5] P. D. Yang, H. Q. Yan, S. Mao, R. Russo, J. Johnson, R. Saykally, N. Morris, J. Pham, R. R. He, and H. J. Choi, Adv. Func. Mat. 12, 323 (2002).

[6] X. D. Wang, C. J. Summers, and Z. L. Wang, Nano Lett. 4, 423 (2004).

[7] Y. C. Kong, D. P. Yu, B. Zhang, W. Fang, and S. Q. Feng, Appl. Phys. Lett. 78, 407 (2001). 
[8] G. X. Qian, K. F. Huo, J. J. Fu, T. F. Hung, and P. K. Chu, J. Appl. Phys. 104, 014312 (2008).

[9] B. L. Cao, Y. Jiang, C. Wang, W. H. Wang, L. Z. Wang, M. Niu, W. J. Zhang, Y. Q. Li, and S. T. Lee, Adv. Func. Mat. 17, 1501 (2007).

[10] K. Huo, Y. Hu, J. Fu, X. Wang, P. K. Chu, Z. Hu, and Y. Chen, J. Phys. Chem. C 111, 5876 (2007).

[11] Y. Liu, Z. Chen, Z. Kang, I. Bello, X. Fan, I. Shafiq, W. Zhang, and S.-T. Lee, J. Phys. Chem. C 112, 9214 (2008).

[12] L. E. Greene, M. Law, D. H. Tan, M. Montano, J. Goldberger, G. Somorjai, and P. Yang, Nano Lett. 5, 1231 (2005).

[13] H. Yoon, K. Seo, H. Moon, K. S. K. Varadwaj, J. In, and B. Kim, J. Phys. Chem. C 112, 9181 (2008).

[14] H.-S. Chung, Y. Jung, T. J. Zimmerman, S.-H. Lee, J. W. Kim, S. H. Lee, S. C. Kim, K. H. Oh, and R. Agarwal, Nano Lett. 8, 1328 (2008).

[15] T. Castro, R. Reifenberger, E. Choi, and R. P. Andres, Phys. Rev. B 42, 8548 (1990).

[16] P. Buffat and J. P. Borel, Phys. Rev. A 13, 2287 (1976).

[17] P. R. Couchman and W. A. Jesser, Nature 269, 481 (1977).

[18] H. X. He, H. Zhang, Q. G. Li, T. Zhu, S. F. Y. Li, and Z. F. Liu, Langmuir 16, 3846 (2000).

[19] G. Seryogin, I. Shalish, W. Moberlychan, and V. Narayanamurti, Nanotechnology 16, 2342 (2005).

[20] K. Vanheusden, W. L. Warren, C. H. Seager, D. R. Tallant, J. A. Voight, and B. E. Gnade, J. Appl. Phys. 79, 7983 (1996).

[21] I. Shalish, H. Temkin, and V. Narayanamurti, Phys. Rev. B 69, 245401 (2004).

[22] C. J. Lee, T. J. Lee, S. C. Lyu, Y. Zhang, H. Ruh, and H. J. Lee, Appl. Phys. Lett. 81, 3648 (2002). 

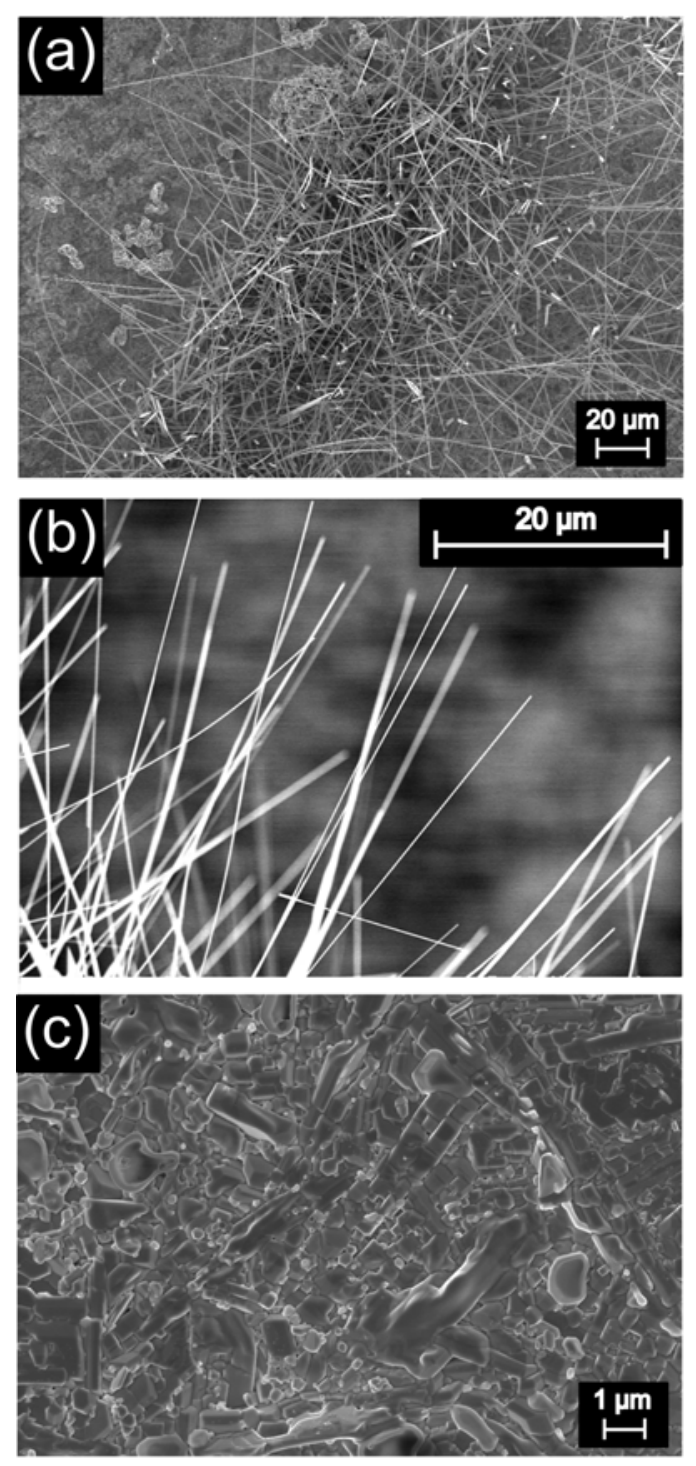

FIG. 2: Scanning Electron Microscopy (SEM) images using a Zeiss Ultra 55 at $5 \mathrm{kV}$ with a working distance of $8 \mathrm{~mm}$. (a) Characteristic SEM image of $\mathrm{ZnO}$ nanowires grown on Mo foil containing a ring of $5 \mathrm{~nm} \mathrm{Au}$ particles. The wire growth is catalytic in that growth occurs only on the ring of nanoparticles and not on the bare metal foil. (b) $\mathrm{ZnO}$ nanowire growth on Mo foil shown at higher magnification. Wires on this sample ranged in length from 10-30 $\mu \mathrm{m}$ and in diameter from 100-300 nm; the full range of diameters that we observed was $40 \mathrm{~nm}$ to $1 \mu \mathrm{m}$. (c) Post-growth SEM image of Mo foil containing $30 \mathrm{~nm}$ Au particles, which shows only bulk ZnO crystal growth and no nanowires. 


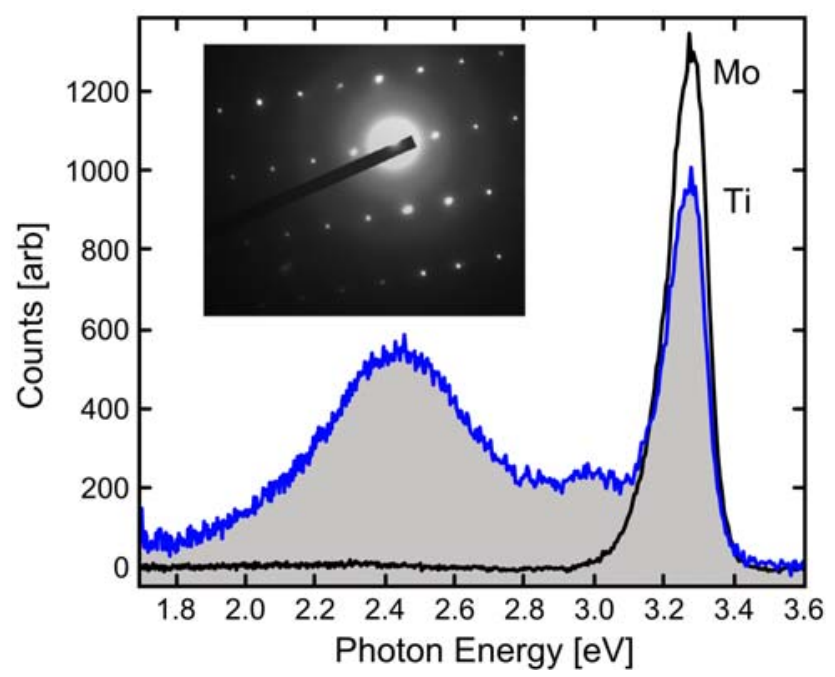

FIG. 3: (Color online) Photoluminesence spectra from ZnO nanowires grown on Mo and Ti foil substrates showing characteristic band-edge luminescence near $3.3 \mathrm{eV}$. A broad sub-band peak near $2.5 \mathrm{eV}$ was observed in wires grown on $\mathrm{Ti}$ foil but not in those grown on Mo foil. We believe this is a surface area effect caused by the smaller diameter of the wires grown on Ti foil. The sample was excited using a $325 \mathrm{~nm}$ He-Cd laser. (Inset) Transmission electron microscopy electron diffraction image of a $\mathrm{ZnO}$ nanowire showing single-crystalline structure. The c/a ratio is approximately 1.64, characteristic of a wurtzite lattice. 